\title{
Killer Serials: Did Electronic Journals Really Destroy the University Press?
}

\author{
Elisabeth A. Jones \& Paul N. Courant \\ University of Michigan Libraries \\ 818 Hatcher Graduate Library South \\ Ann Arbor, MI 48109 \\ elisjone@umich.edu, pnc@umich.edu
}

\begin{abstract}
Given the rapidly changing economics of scholarly communication in the digital age, the importance of accurate, specific data on the resource flows within this realm has become increasingly important. Both the producers and the collectors of scholarly information require accurate information in order to nimbly navigate their changing roles in advancing the progress of knowledge. Two key actors in this area are university presses and academic libraries, which both hold keystone roles in scholarly communications, as disseminators and conservators of scholarship, respectively. This paper describes an exploratory study examining one contentious aspect of the relationship between these two actors: trends in purchases of university press books by academic libraries. It does so in order to provide an empirical basis for evaluating frequent claims by publishers that declines in libraries' monographic purchasing over the past three decades can be held primarily responsible for the declining economic fortunes of university presses over the same period. The results of this analysis indicate that this relationship is not clear-cut, for at least two reasons: first, to the extent that purchasing reductions have occurred, they have occurred much more recently than prior accounts have suggested, and second, purchasing trends vary significantly between different libraries and between different sizes of university press.
\end{abstract}

\section{Keywords}

Scholarly communication, scholarly publishing, academic libraries, university presses, books, electronic journals, information economics.

\section{INTRODUCTION}

In scholarly publishing circles, the story of how university

ASIST 2013, November 1-6, 2013, Montreal, Quebec, Canada.

This work is licensed under the Creative Commons Attribution 3.0 Unported License. To view a copy of this license, visit http://creativecommons.org/licenses/by/3.0/ or send a letter to Creative Commons, 444 Castro Street, Suite 900, Mountain View, California, 94041, USA. presses have been crushed under the weight of declining library monograph budgets has achieved the status of a canonical truth: no evidence necessary; everybody knows it's a fact. Indeed, in a 2010 article, publishing consultant Joseph Esposito frames this narrative explicitly as a parable or fable:

Once upon a time, before predatory commercial journal publishers began their assault on the purchasing budgets of academic libraries, libraries could be counted on for a certain level of sale of academic monographs. That virtual guarantee permitted university presses to support the research activities of scholars, especially in the humanities. But when the library budgets began to get gobbled up by the villainous commercial houses, monograph sales plummeted, taking the fortunes of university presses with them. Thus, the goal is to find a new business model, a "sustainable" one, which would enable the presses to continue with their historical support of the research community.

And, he concludes, "That narrative is largely true" (Esposito, 2010). But is it? Can the decline and fall of U.S. university presses truly be traced so directly to trends within library collection budgets?

We will return to these questions in a moment, but first it will be useful to more fully explain the importance of having accurate answers to them.

Put simply, we care about the health of university presses because we care about how knowledge is produced and distributed. The parable that we examine in this paper argues that academic libraries have become unable or unwilling to support the traditional mechanisms of publication in the humanities and humanistic social sciences, in part because their expenditures on electronic journals, mostly in scientific fields, are crowding out academic monographs. ${ }^{1}$ If the parable is true, then the root

1 Throughout this paper we utilize the definition of "monograph" common in the library world: any bookshaped volume that is not a rebinding of other materials (e.g., Kyrillidou et al., 2012, pp. 106-107). 
of the widely-touted crisis in academic humanities lies within the academy itself. In the "good old days," the story goes, libraries' purchases of scholarly monographs were sufficient to keep the industry viable. The economic peril confronting university presses, then, has arisen not from anything that those presses have done, nor from the general malaise in the publishing industry, but because an important source of support - guaranteed sales to academic libraries has been withdrawn. In this context, it makes sense for press directors to importune provosts and vice-presidents for supplementary funding to restore the support necessary to assure the vitality of knowledge production and distribution in the "book" fields.

However, if the malaise facing university presses derives from other causes, a case could be made that what is called for is change in the way that publication in these fields is undertaken - probably in the direction of electronic production and distribution, and plausibly including greater use of open access. The response of academic institutions to emerging weakness in the system of scholarly communication will depend in part on the causes of the problems, however, and thus accurate diagnoses of those causes are essential. In particular, analyses like the one offered here will help to shed light on whether increased use of electronic production and distribution is a root cause of the crisis in scholarly communications or a plausible cure (or neither, or both).

\section{RATIONALE FOR THE STUDY}

The relationship between library budgets and the relative health of university presses is a topic on which one can find many claims, but little verifiable data. Many of these claims conform quite directly to the form and overall thrust of Esposito's parable above: university presses are dying because rising electronic serials costs have eaten up all the library budgets and left no money to purchase monographs. Some add a few numbers to the mix, generally in the form of "university presses used to be able to count on selling $\mathrm{X}$ (large) number of copies of every book to libraries, but now they can only sell Y (small) number of copies - and that's just not sustainable." Perhaps unsurprisingly, press directors and editors seem especially quick to assert this type of argument - library purchasing, after all, tends to be well out of the scope of factors under the press's control, and thus would shift the burden of finding a solution to declining and often negative margins beyond the inner workings of the press itself (e.g., Dougherty, 2010; Hitchcock, 1999; Pochoda, 2010; Thatcher, 1995; Wasserman, 1998).

Superficially, such claims can seem quite reasonable. After all, most of the pieces are there. Serials prices have spiked over the past few decades: the Association of Research Libraries (ARL) reports a 402\% climb in library expenditures in this area between 1986 and 2011. And while ARL members' monographic expenditures have also risen over that period (by a much smaller 71\%) the rise in actual volumes purchased is a more anemic $10 \%$
(Association of Research Libraries, 2011). On the basis of such data, the claim that monographic purchasing accounts for an ever-decreasing share of library budgets seems perfectly reasonable - and in fact we believe that this claim is substantially correct.

However, once one examines the overall picture in a bit more detail, several questions emerge. In the literature review that follows, we suggest that three elements of the narrative linking university press declines to library purchasing particularly demand further scrutiny:

1. The fit between university press publishers' stories of how many more volumes they used to sell to libraries in "the good old days" and the practices of academic library collection development on a system-wide level,

2. The validity of generalizing about the purchasing patterns of all college and university libraries based solely on ARL data, and

3. The extent to which trends in libraries' overall monographic purchasing actually concur with trends in their purchasing of university press monographs.

\section{"The Good Old Days"}

Many publisher-oriented accounts link the fate of university presses extremely tightly to trends in library purchasing, claiming, for example, that "the single greatest reason our [university presses'] financial problems have become severe is because declining library sales have dramatically decreased the number of copies we can print" (Wasserman, 1998). But just how much have these numbers declined? Reports vary.

Wasserman claims that libraries used to account for sales of 700 copies of each book, but can now only be relied upon to buy 200 (1998). Hitchcock concurs with the latter number, but places the starting point at 800 (1999). Neither of these authors, however, places a date on "the good old days," beyond vaguely claiming that this was "once" true (Hitchcock, 1999). In 2002, Smallwood quotes Beatrice Rehl of Cambridge University Press as placing a more specific timeline on this downturn, with the starting point around 1992, while concurring with the rough sales figures cited above. Thompson, however, dates the decline back to the 1970s, when "academic publishers would print between 2000 and 3000 hardback of a scholarly monograph," compared to 400-500 by the early 2000s (Thompson, 2005, pp. 93-94) - and of course only a portion of those would be sold to libraries, bringing us back to the 200-volume range for the recent period. Underlying these trends, publishers point to declines in libraries' standing orders. As Smallwood summarizes, the argument goes that "Libraries that once had standing orders to buy everything a certain press published are picking and choosing more carefully. At other places, like the University of California, one copy of a book is being purchased for the entire system, instead of copies for each campus" (2002). 
These claims raise a number of questions from the library perspective. First, how common has it ever been, truly, for a library to have a standing order for literally everything a press produced? Even large, well-funded libraries with extensive standing orders (called "approval plans") generally have some sort of collection management strategy that involves a greater emphasis on some subject areas than others. And further, the official group of large, elite libraries, ARL, has only 126 members. Thus, the question arises: even if all of the ARL libraries were buying two copies of everything a press produced (unlikely on its face), to which institutions were the other 400-500 library sales for every single book being made? For smaller libraries, such comprehensive collecting would never have been possible - they would have had neither the budget nor the shelf space to accommodate it. So where were these sales going? The current study will provide some empirical data for examining these questions - and the data tend to confirm the suspicions just raised.

\section{Generalizing from ARL Data}

Where analyses have extended beyond internal publisher data and anecdote and utilized additional figures from the library purchasing end, there is an understandable but troublesome tendency to rely exclusively on the (admittedly excellent) statistical resources provided by ARL. For example, a 2007 study by Greco, Jones, Wharton, and Estelami asserts that it draws upon "reliable statistical data from the ARL for all books and for university press books (i.e., scholarly monographs) for the academic (college and university) library market" (2007, p. 272). But this claim is extremely over-broad. Covering only $108^{2}$ of the 3689 college and university libraries in the United States (American Library Association, 2013; Kyrillidou, Morris, \& Roebuck, 2012), ARL data do not accurately reflect the behavior of all academic libraries and their purchasing patterns, and indeed, they are not intended to do so.

The Association of Research Libraries is comprised exclusively of libraries with large collections and budgets, relative to the rest of the academic library world (Kyrillidou et al., 2012). The most recent edition of the ARL Statistics reports the median library materials expenditure for its member institutions in 2010-11 was nearly $\$ 10.9$ million, up from $\$ 10.5$ million in the previous year (Kyrillidou, Morris, \& Roebuck, 2011, p. 44; Kyrillidou et al., 2012, p. 44). By contrast, if one examines the equivalent figure for the considerably broader set of 324 doctorate-granting institutions tracked by the Association of College and Research Libraries (ACRL), the figures per institution are much smaller. In that group - which itself represents the

\footnotetext{
2 Although ARL has 126 members in total, 18 of those institutions are outside the United States (in Canada), and are not included so as to make the ARL figure more accurately comparable to the larger ALA-provided figure, which does not include non-U.S. libraries.
}

larger-sized end of the ACRL institutional membership the median 2010 library materials expenditure is just over \$3.8 million (Association of College and Research Libraries, 2011, author-calculated value). ${ }^{3}$ Many if not most of these libraries would never have had the resources to engage in the sort of comprehensive university press monograph collecting that is alleged to have occurred on a widespread basis - and even if they had, it is far from clear that their budgets would have extended far enough to engage significantly in the "big deal" electronic serials contracts that presses say ended this alleged history of comprehensive collecting.

And in fact, there are many more small libraries than large ones. ACRL tracks more than 1600 academic libraries of widely varying sizes (Stewart, 2011, p. 73), and at least 1400 of them are smaller than the smallest member of ARL. It is thus a priori unlikely ARL statistics can be generalized to this much larger population of libraries. We try to correct this problem in the analysis presented below.

\section{University Press Monographs vs. Monographs in General}

Also problematic, we suggest, is the implicit equivalency drawn between university press books and books in general within these discussions. Based on the authors' collective experiences in academic library administration and collection management, we would contend that such an equivalency is unlikely to obtain. As noted earlier, libraries' monographic purchasing has declined relative to serials over the past few decades; we do not dispute this. However, we think it unlikely that university press books would be among the first on the chopping block in acquisitions by academic institutions. In fact, we would expect quite the reverse - that virtually every other kind of monograph would be cut before those published by university presses. Academic libraries (and the librarians who run them and faculty they serve) tend to be oriented towards high-quality scholarly work that is the stock in trade of university presses, and generally would prefer not to cut their purchases of these types of books except as a last resort. In this study we provide specific data on libraries' purchasing of university press monographs in particular over the last 25 years, to see whether the trend for these monographs is truly in any way equivalent to the trend for monographs in general.

\section{RESEARCH QUESTIONS}

In view of the questions and concerns raised above, this paper seeks to shed empirical light on some of the economic trends at play in this sphere. In particular, we explore the following questions:

\footnotetext{
${ }^{3}$ Equivalent calculations for ACRL members at Master's-, Baccalaureate-, and Associates-granting institutions would undoubtedly produce still lower figures.
} 
1. Has there actually been a downturn in library purchasing of university press books? And if so, does it temporally track with the sharp increases in serials prices in the 1980 s and 1990 s, as is often claimed?

2. Are the purchasing trends for university press books consistent across:

a. Different-sized academic libraries (in terms of materials budgets)? and/or

b. Different-sized university presses (in terms of title output)?

\section{METHODOLOGY}

Because university presses do not tend to share their sales data at any level of granularity (if they share it at all), we approached this problem utilizing more broadly accessible resources: the annual Directory of the Association of American University Presses (AAUP), ACRL's annual Academic Library Trends \& Statistics, and OCLC's WorldCat tool (using the FirstSearch interface). Each of these data sources - particularly WorldCat - has its quirks and limitations, but together they provide a useful window into trends in scholarly communications in recent decades one that goes beyond existing rhetoric and parables. Indeed, the methodology we employ here is itself a contribution of this work, as it provides a replicable and extensible way of providing empirical insight on these issues without requiring access to confidential data sources that are infrequently shared.

\section{Sampling}

Two samples were used for this study: one of university presses and one of academic libraries. The sampling methodologies differ; we will discuss each in turn.

\section{University Presses}

In order to develop a basis for selecting a sample of university presses, publication output numbers for each AAUP member press based at a U.S. university ${ }^{4}$ were gathered from volumes of the AAUP's Directory covering the years from 1985-2010 inclusive. Each volume of the directory provides two years' worth of publication data, and these data overlap: for example, the directory for 2011 provides data for 2009 and 2010, while the directory for

\footnotetext{
${ }^{4}$ This excluded all non-U.S. university presses (including those with U.S. footprints - i.e., Oxford and Cambridge, which also represent extreme outliers in terms of output and finances) as well as all scholarly association and freestanding research institute presses (e.g. Brookings Institution, American Historical Association). As all but one of the above-cited press director claims about this phenomenon have emerged from U.S. university-based presses (and none from association presses), this seemed a reasonable limitation to put in place in examining these claims.
}

\begin{tabular}{|c|c|}
\hline Sample Presses & $\begin{array}{c}\text { Mean } \\
\text { Books/Year }\end{array}$ \\
\hline Princeton University Press & 235.2 \\
\hline Johns Hopkins University Press & 183.2 \\
\hline University of Washington Press & 102.5 \\
\hline University of North Carolina Press & 90.3 \\
\hline Duke University Press & 90.2 \\
\hline University of Minnesota Press & 76.5 \\
\hline University of Wisconsin Press & 60.9 \\
\hline University Press of Mississippi & 58.3 \\
\hline Pennsylvania State University Press & 57.8 \\
\hline Southern Illinois University Press & 52.8 \\
\hline University of Missouri Press & 48.8 \\
\hline Ohio University Press & 45.8 \\
\hline University of lowa Press & 33.9 \\
\hline Georgetown University Press & 27.5 \\
\hline Northern Illinois University Press & 18.3 \\
\hline
\end{tabular}

Table 1

2010 provides data for 2008 and 2009. When these overlapping numbers differed, the figure from the more recently published directory was used. This provided publication output numbers for 96 presses in total.

Of these 96 presses, however, only 63 had complete data for the entire period from 1985-2010. Gaps occurred for two basic reasons, which are difficult to distinguish from one another purely on the basis of the directory data: either (1) the press did not exist for the entire period (i.e., it began operation after 1985, shut down before 2010, or both) or (2) the press was not a member of the AAUP for the entire period. In order to enable the observation of trends across the entire period, the population was thus limited to the 63 presses with complete data prior to sampling.

In order to ensure the representation of a range of different sizes of press, the presses were then rank-ordered by mean number of titles published per year, and divided into thirds (Top, Middle, and Bottom). Within these thirds, a random number generator was used to select five presses from each set. Ultimately, we looked at the presses listed in Table 1.

\section{Academic Libraries}

Initially, to test the methodology, we began by running the numbers for two university libraries familiar to us, at the University of Michigan and the University of Washington. Once we were sufficiently convinced of the merits of the general approach, we expanded the study to include six additional libraries of more diverse sizes. In order to obtain a broad distribution of library sizes, we first rank-ordered the list of 324 libraries included in ACRL's 2010 Trends \& Statistics for Carnegie Classification: Doctorate-Granting Institutions by total library materials expenditures, and then divided that list into quartiles. Not wishing to discard data 


\begin{tabular}{|c|c|}
\hline Sample Libraries & Materials Exp. (2010) \\
\hline University of Michigan & $\$ 23,002,928$ \\
\hline University of Washington & $\$ 14,841,396$ \\
\hline Wayne State University & $\$ 8,601,311$ \\
\hline University of Utah & $\$ 6,728,095$ \\
\hline University of North Dakota & $\$ 3,679,894$ \\
\hline Eastern Michigan University & $\$ 2,997,353$ \\
\hline Texas Woman's University & $\$ 1,160,169$ \\
\hline Barry University & $\$ 723,143$ \\
\hline
\end{tabular}

Table 2

already collected, we retained the two institutions already examined, which were in the top quartile, ranked 5 and 23, respectively. In order to select the remaining six, we targeted the same regions of the other three quartiles (libraries with in-quartile ranks of 1-6 and 20-25), then rolled a die to select one library from each region. The resulting list of libraries appears in Table $2 .^{5}$

\section{Data Collection}

To look at purchasing patterns, we utilized OCLC's WorldCat database via its subscription-based FirstSearch interface. WorldCat is the world's largest union catalog, indexing and aggregating the collection contents of thousands of libraries worldwide (OCLC). Its use in this context has several advantages, but most important among them is WorldCat's relative uniformity as a tool for extracting data about this diverse set of libraries especially when compared to alternate approaches such as using each library's local catalog interface. Additionally, WorldCat has a solid record as a resource for tracking aggregate collection trends (e.g., Lavoie, Connaway, \& Dempsey, 2005; Lavoie, Malpas, \& Shipengrover, 2012), and has recently been recommended as a useful tool for analysis on the topic at hand by the author of the parable cited in the introduction to this paper (Esposito, 2012). Though the database has several limitations, discussed further below, it remains the best resource currently available for this type of analysis.

Within the FirstSearch interface, data were collected by manually running repeated "Expert Search" queries to determine how many works each library currently owns, published by each press, in each year from 1985-2010. To illustrate, a single iteration of the query might look like this:

5 Although it would likely have been methodologically preferable to have taken a census of these institutions rather than a sample, such a widening of scope was not feasible at this time due to the relatively labor-intensive manual procedure used for data collection. Should we choose to continue this research with a larger sample, it would be useful - even, perhaps, necessary - to automate this process using scripting or by tunneling in through the WorldCat API (or both).
- Publisher phrase $(\mathrm{pb}=)$ : Duke University Press

- Year: 2002

- Limit type to: Books

- Limit availability to: $\mathbf{E Y E}^{\mathbf{6}}$

This search was iterated across the years 1985-2010 for each sample press within each sample library. Each time it was run, a record count would appear at the top of the results page, reflecting, roughly speaking, the number of books that library had purchased from that press in that year (there are some caveats and limitations here, to which we will return in a moment). For example, the search above would tell us that Eastern Michigan University owns 39 books published by Duke University Press in 2002. Extended across 25 years, 15 presses, and 8 libraries, and combined with the AAUP data on press outputs described above, this procedure reveals a number of trends in library purchasing, several of which tend to challenge the conventional wisdom among publishers described above.

\section{Database Limitations}

As noted, the WorldCat database has some significant quirks and limitations, three of which we will address briefly here.

First, the WorldCat data are simply noisy as a general rule - prone to minor errors and riddled with duplicate records for identical items. For example, sometimes a search limited to 1988 will pull up items listed as 1987, or viceversa; or sometimes the press name will not appear in the records exactly as it appears in the query (e.g. "Duke University Press" vs. "Duke University"). This will undoubtedly mean that some title counts collected as described above - perhaps even many - will be off by a title or two. However, because such errors seem to be fairly randomly distributed across the set of records in question, it is not clear that this noise would bias the shape of the overall trend observed in any systematic way. Additionally, because this methodology searches within one library at a time, we would not expect duplicate records to be a significant issue here: generally speaking, WorldCat record duplication occurs when two different libraries upload slightly different records for the same volume. Within a single library, most of this duplication should be absent.

A second issue with the WorldCat data is change over time: libraries sometimes purchase books years after they were published, and often remove books from their collections as they become obsolete or less useful than they once were. Thus, the fact that Eastern Michigan now owns 39 books from 2002 from Duke University Press does not necessarily mean that all of those books were purchased in or around

${ }^{6}$ EYE is the OCLC library code for Eastern Michigan University. All WorldCat-participating libraries have such a three-character code. 
2002. Nor does it mean that 39 was all they ever had - they could have discarded some volumes over the past eleven years. The former issue is of small concern for this study: the question of exactly when books were purchased is not as important here as the fact that they were purchased at all. The latter issue has the potential to be more troublesome, as it could throw off the observed trend: the numbers of books still held from earlier years, given collection weeding over time, could be smaller than the number that were initially purchased from those presses in those years. If library purchasing were actually flat, this factor could make it look as though it was increasing, because the older a book is, the more time the library would have had to discard it, thus artificially lowering purchasing numbers for years further in the past. However, we are confident that this issue is mitigated by the fact that libraries rarely remove records from WorldCat, even when they have removed the book from their collection and the record from their local catalog. A library systems specialist at our own institution tells us that our library virtually never removes records for deaccessioned books from WorldCat, and that this situation is quite common among our peer institutions. Thus, as a picture of purchasing trends rather than the actual shape of the current library collection, WorldCat may actually be a more accurate instrument for assessing these older volumes than each institution's local catalog, which tends to be kept more up to date.

Finally, a third phenomenon to be aware of with regard to WorldCat data is the possibility that some libraries may have backlogs in entering newly collected materials into the system. This would create problems mainly for recent years' data, and was a significant reason for cutting off the time period to be examined at 2010. It is possible that some of the libraries in our sample may have backlogs in updating records on WorldCat that extend further back than 2010, however, and it would thus be wise to take the years beyond about 2008 with a grain of salt: what look like declines in purchasing may at least partially reflect delays in records management.

\section{FINDINGS}

These data allow us to address the two research questions posed earlier, regarding purchasing trends and the effect of institution size. We will discuss each in turn.

\section{Trends in Library Purchasing}

Our first research question asked whether there had actually been a downturn in library purchasing of university press books since 1985, and if so, whether that decline was temporally coincident with the sharp increases in serials prices that began in the 1980s and 1990s.

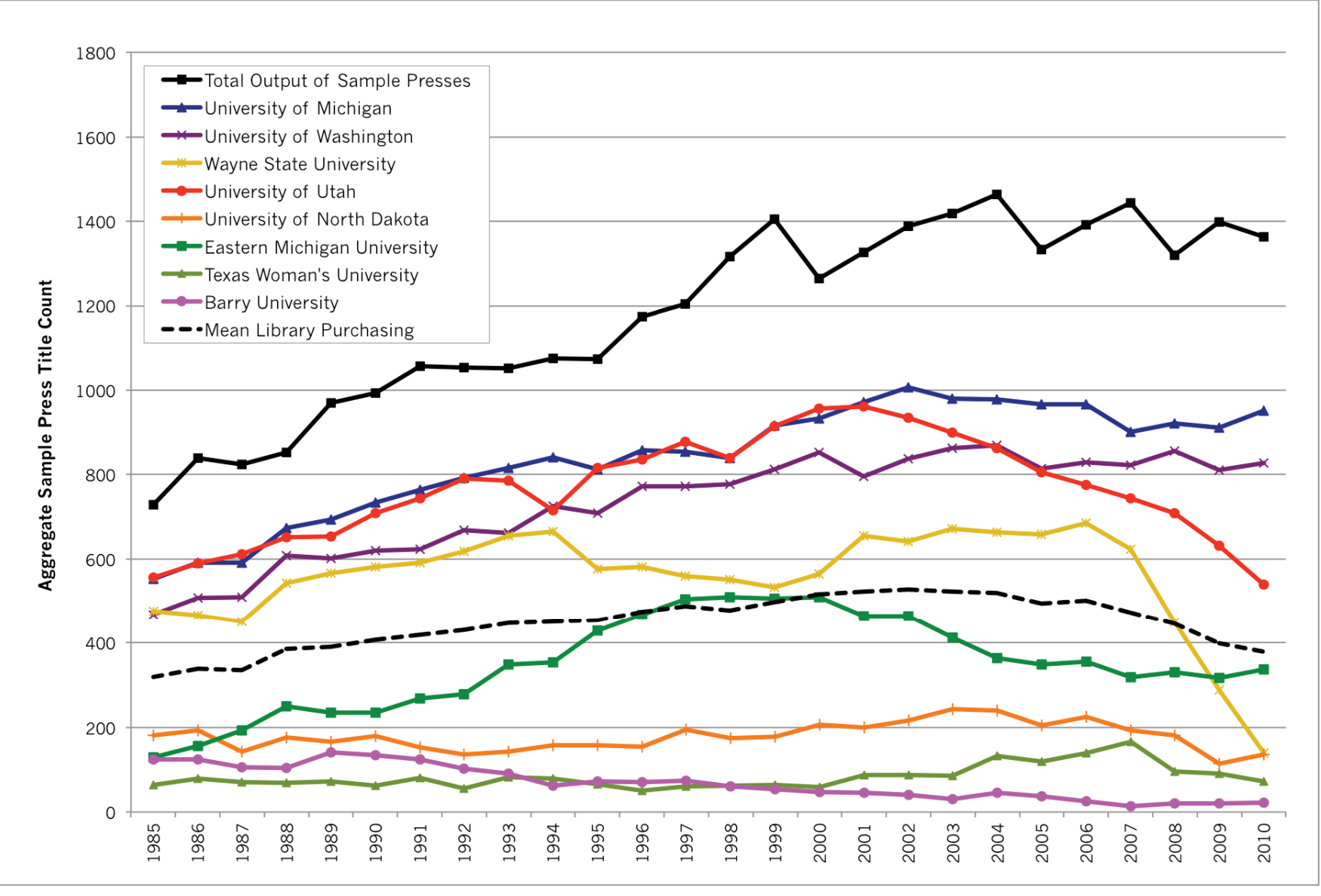

Figure 1: Trends in Sample Library Purchasing of Sample Press Titles, 1985-2010 


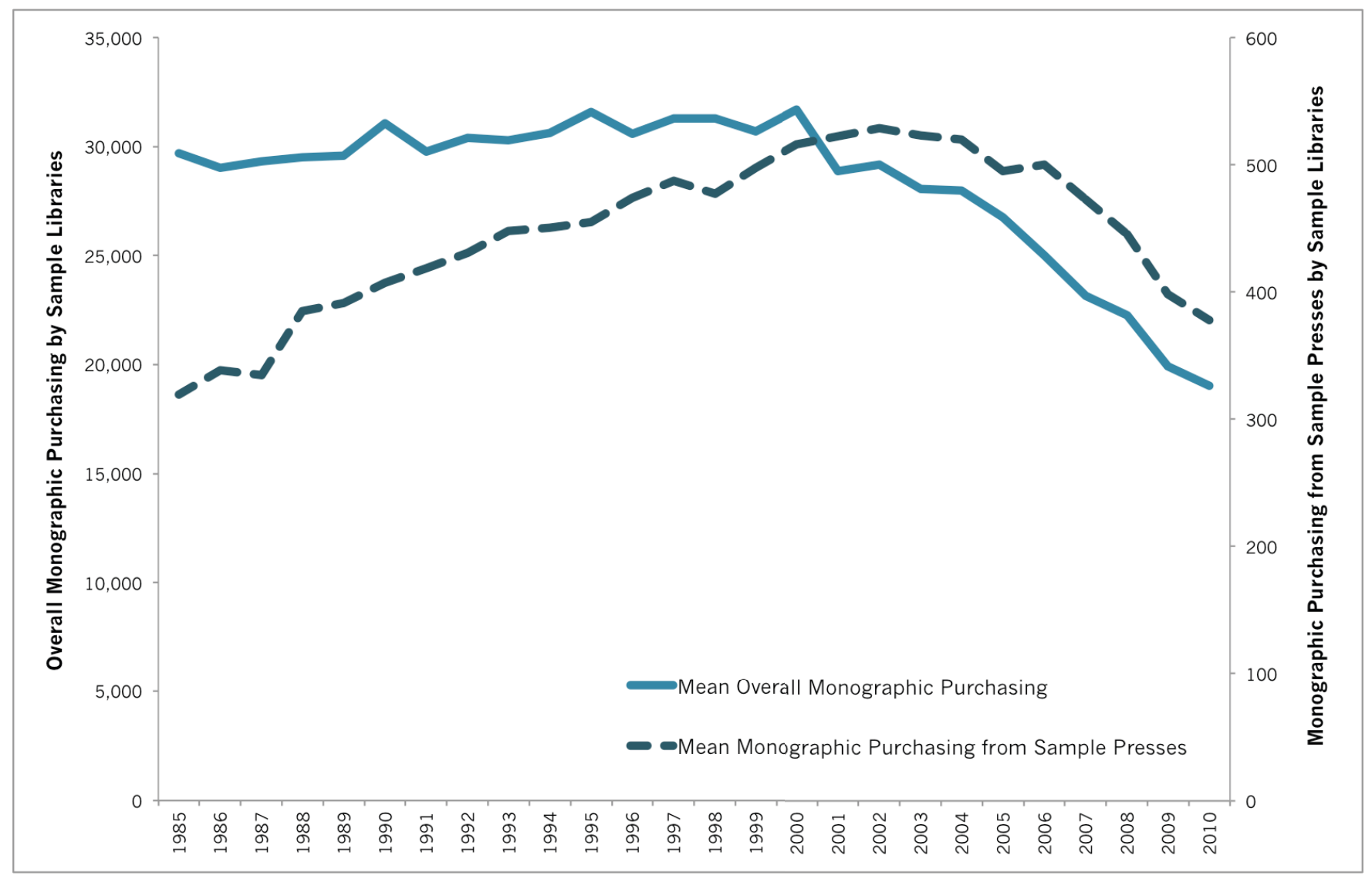

Figure 2: Mean Overall Monograph Purchasing by Sample Libraries vs. Mean Sample Press Monograph Purchasing by Sample Libraries, 1985-2010

To the first part - whether there has been a consistent decline - we would have to respond that it depends on the library: each institution in the sample shows its own trend, as illustrated in Figure 1. While some libraries show declines, purchases at others have risen throughout the period, and still others have gone through a less consistent set of peaks and valleys. On average (as illustrated by the black dashed line), the overall trend appears to be a gradual increase in library purchasing up to the early 2000s, followed by a gradual decrease after that point.

However, quite intriguingly, the answer to the second question would appear to be a decisive no: only one library in the sample - the very smallest, at Barry University shows a consistent decline in purchasing from university presses extending back to the 1980s. To the extent that any of the other libraries cut their purchasing from the sample presses, they tended to do so later, mainly around either 2000 or 2007 - dates which, likely not coincidentally, mark the beginnings of the two most recent major U.S. economic downturns. $^{7}$

\footnotetext{
${ }^{7}$ This correlation becomes especially compelling when one considers that these are publication dates - the purchase dates could well have been the following years, 2001 and
}

The suggestion of a later starting date for reductions in library purchasing from university presses is further substantiated by the trend in mean purchasing already noted, which rises steadily up to about 2000, goes flat for a few years, and only begins to decline in earnest after about 2004. Notably, this trend differs significantly from the mean trend for overall book purchasing within these same libraries. Based on data gathered using the same WorldCat procedure described above, substituting "Material Type = Book" for the Publisher filter, a rough count of total book titles purchased by each of the sample libraries over the study period was gathered. In Figure 2, the mean of these totals (lighter/solid line, left axis) is plotted alongside the mean of the totals for the sample presses (darker/dashed line, right axis). The relationship between the two lines is extremely intriguing. Throughout the 1980s and 1990s, it would appear, mean overall book purchasing among these libraries was essentially flat, with a significant decline starting only in about 2000. During this entire period of plateau, however, the libraries' mean purchasing from the sample university presses was steadily increasing; indeed, it continued to increase for a few more years after the

2008, which were both worse economically than the respective years before. 
institutions' overall monographic purchasing began to decline, only beginning its own downturn after 2002, and not declining sharply until 2006. This data, gathered from an identical group of libraries using the same data source, provides compelling evidence for our earlier assertion that university press books were likely to be privileged in terms of purchasing by academic libraries. Libraries' overall monographic purchasing may have gone flat in the 1980s and declined after 2000 , but based on these data, the same cannot be said for their purchasing of university press monographs. Cutting those purchases truly does seem to have been a strategy of last resort, likely linked more closely to the overall economic conditions of the past decade than to the rising serials costs which came much earlier.

This leads us to ask why, if library purchasing from university presses was rising until the early 2000s - even bucking the trend of flat purchasing in other types of monographs - the leaders of university presses have been claiming that libraries started slashing their purchases of university press monographs around 1992. One plausible answer is suggested by the difference in slope between the trend lines for library purchasing and the line tracking press output in Figure 1. Even as these libraries continued to increase their average and overall purchasing from the sample presses throughout the 1990s, the presses had been accelerating their title output at a much higher rate. Because of this, from the press perspective, it may have seemed as though libraries were purchasing fewer books. However, such an assertion is only supportable on a percentage basis; the real numbers of titles purchased were still rising. These percentage trends are pictured in Figure 3. As it illustrates, throughout the period, libraries were purchasing a decreasing number of books per title published, even though they were not purchasing any fewer books in total, and in some cases were purchasing more.

Further, the leftmost percentages depicted Figure 3 also confirm our skepticism regarding the publisher tales of the "good old days:" that is, no library, not even the very largest in the sample, purchased comprehensively from these presses at any time in these 25 years. The highest point value for any of the libraries was for the University of Michigan in 1988 , when it purchased $79 \%$ of all the titles published by the sample presses. But on average, among this sample of libraries, the highest percentage purchased from the sample presses was 45\% (again in 1988). So what does this mean for presses' claims that they used to be able to count on libraries to buy 700-800 copies of any monograph (Hitchcock, 1999; Wasserman, 1998)? Where were those books going? Some undoubtedly would have been sold to libraries outside the United States, which are not included in the population considered here. Some books may have sold multiple copies to at least some libraries, but these would have been fairly exceptional cases in the

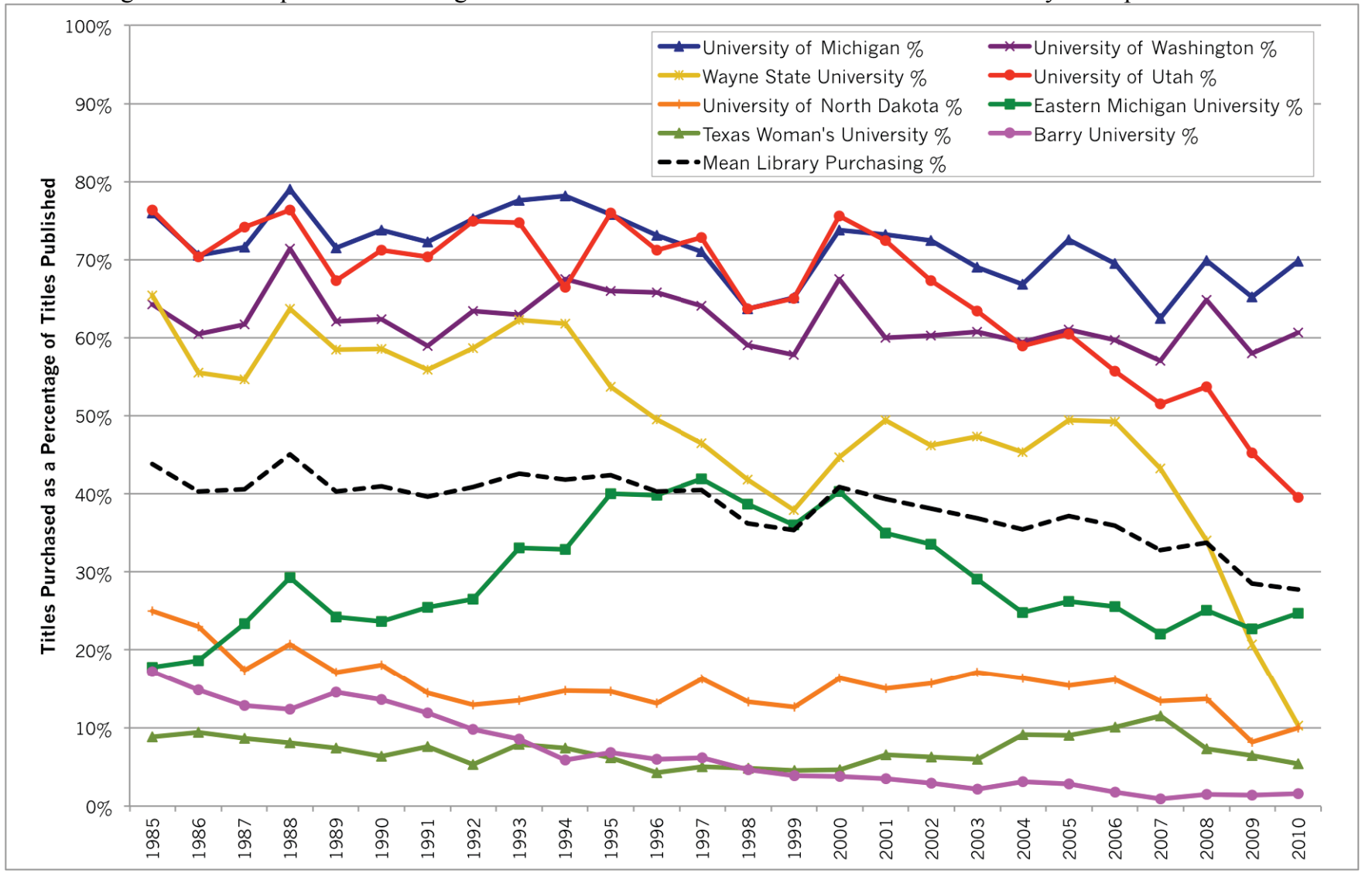

Figure 3: Trends in Sample Library Purchasing of Sample Press Titles, as Percentage of Press Output, 1985-2010 
university press publishing world (e.g., Esposito, 2012). But within our sample, only the libraries above the median ever bought more than $50 \%$ of the presses' titles. Extrapolating back to the population of 324 academic libraries from which this sample was drawn, this means that we would only expect at most 162 of them to have ever bought more than half of the presses' output. And then we must consider the fact that the population that we are studying here only extends to doctorate-granting institutions. Among baccalaureate- and associate's-granting institutions, budgets tend to be lower on average, implying that there is a much larger set of libraries that, based on the data gathered here, we would never have expected to purchase more than 30 $40 \%$ of university press output, at the very most. Indeed, the two smallest libraries considered here, at Texas Woman's University and Barry, only rarely purchased more than $10 \%$ of university press titles over the 25 -year period and there are almost certainly many more like them. ${ }^{8}$

\section{Differences Based on Size}

The second set of questions posed at the outset probes the effect of size - both of libraries and of presses. As described above, the size of the libraries for the purposes of this study was measured in terms of materials expenditures, while the size of the presses was measured in mean title output per year. It is not possible to generalize broadly from such a small sample of either institutional type, but the differential trends based on size are nonetheless intriguing, particularly as a potential jumping-off point for future work.

\section{Libraries}

As discussed, each library exhibited its own trend over the 25-year period examined, and only two libraries were sampled from each quartile. It is thus entirely possible that adding further libraries from each quartile would produce significantly different in-quartile trends. However, Figure 4 illustrates quite a consistent set of stories for the observed trends in this sample. On average, the two libraries in the top quartile (University of Michigan and University of Washington) consistently increased their purchasing over the period from 1985-2002, with only a small decline after 2004. The next largest pair (Wayne State University and University of Utah) increased purchases from 1985-1993 and between 1998-2001, with an intervening plateau, slowly declined from 2002-2006, and then fell off a cliff

\footnotetext{
${ }^{8}$ It is of course possible that smaller academic libraries, in aggregate, bought a great deal of university press output in the good old days, and reduced their purchases sharply at some point - indeed, one could study this question using the methods that we outline in this paper. However, even were this true, it would still not support the prevalent notion that it was mainly cutbacks at larger institutions with formerly more comprehensive approval plans that caused the crisis in university press publishing.
}

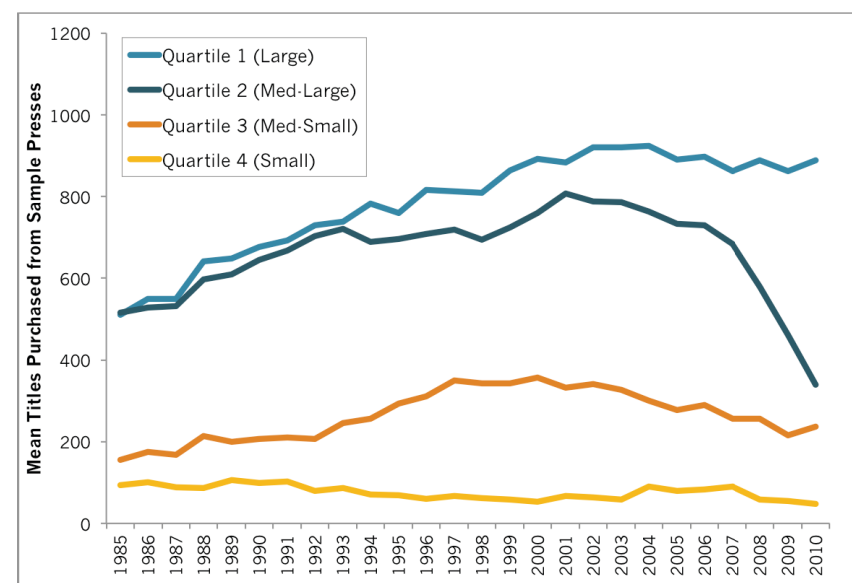

Figure 4: Sample Press Titles Purchased by Sample Libraries Over Time, Averaged by Library Quartile

after that, dropping well below 1985 levels by 2010. The third quartile libraries (University of North Dakota and Eastern Michigan University) also initially rise until about 1997, then plateau up to 2000 and decline thereafter. And finally, the smallest libraries (Texas Woman's University and Barry University) remain essentially flat or in slight decline over the entire period.

Based on these data, the only line that approximates the trend described by publishers - continual decline in purchasing since 1985 - is that for the very smallest size of library. Yet, of course, these small libraries have never purchased anywhere near comprehensively, rarely buying more than $15 \%$ of these presses' books in a given year. Thus, although they follow the publisher-predicted trend, they are unlikely to have independently accounted for the publisher-described reduction in guaranteed sales to libraries - they simply never bought enough books to provide any such guarantee in the first place.

The top line is intriguing for the opposite reason: the magnitude of purchases is in the ballpark of guaranteeing sales, yet the trend is the inverse of what the publishers describe. In fact, the largest libraries' average purchasing declines only quite recently, and even then only slightly so. These libraries - both ARL institutions - are exactly the sort that have tended to purchase more comprehensively over this time period - generally between $60-80 \%$ of the press's titles, as shown in Figure 2 - and they are also the most likely to have entered into the enormous, hugely expensive electronic serials contracts with commercial publishers like Elsevier and Wiley that university press publishers blame for so many of their woes. However, the percentage of books these two libraries have purchased from the university presses examined here has scarcely fallen over time, even after 2000. This trend thus fails to explain the publisher perception of a massive decrease in guaranteed sales to libraries at any time in this period much less in the 1990s, when these libraries were steadily increasing the number of titles purchased from these presses in each year. 


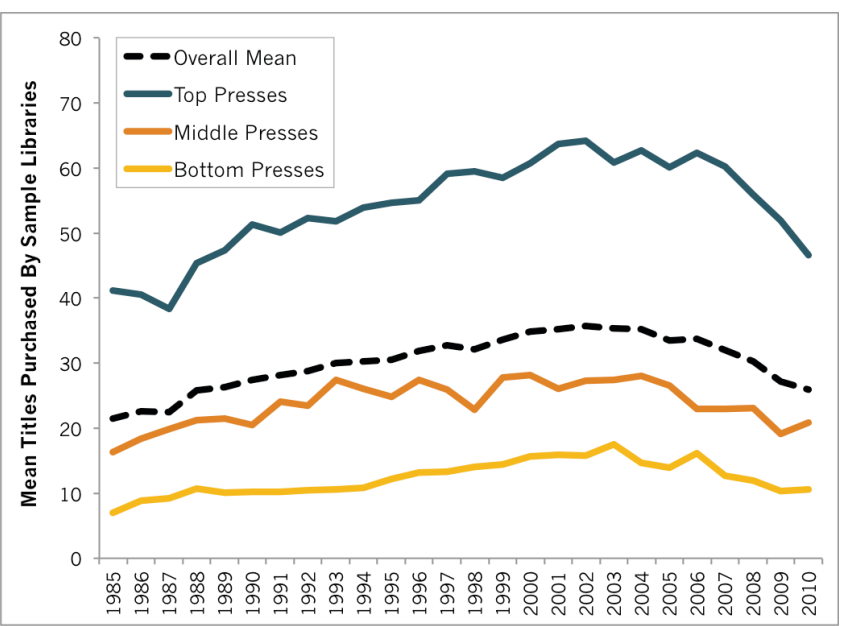

Figure 5: Mean Library Title Counts per Year by Size of Press, 1985-2010

\section{Presses}

Although the limited library sample size still may present issues for interpretation of the data from the press perspective, the sample size for the presses is a bit more representative: the fifteen sample presses account for $23 \%$ of the total AAUP membership for which complete data was available throughout the time period examined. And indeed, one striking difference among the trends for different-sized presses immediately appears in Figure 5. That is, while all sizes of press generally trace the ups and downs of the overall mean trendline (dotted black) both the small- and medium-sized presses appear a bit flatter than that line, while the large presses appear considerably sharper, both in incline prior to 2000 and in decline after 2006. This indicates, at least at a general level, that to the extent that libraries altered their purchasing patterns for university press books over this period, the alterations were much greater for the larger presses' lists than for the smaller ones.

It is also worth recalling that all of these presses, large medium, and small, increased their title output throughout most of this period, only beginning to decline even slightly after 2004. Thus, from the presses' perspective, even a flattening in titles sold to libraries would come across as a decline in sales per title, when compared against the everincreasing number of titles produced. For example, Princeton University Press (the largest in the sample) published 300 books in 2003, and 365 in 2004. Over the same two years, the sample libraries purchased an average of 105 and 104 books from Princeton, respectively - almost literally flat. But from Princeton's perspective, even this consistent level of purchasing might look like a sharp drop in library sales: where in 2003, these libraries had bought an average of $35 \%$ of Princeton's list, in 2004, they bought only about $28 \%$; the real numbers of titles purchased had not declined, but the sales per title published most certainly had.

\section{DISCUSSION}

Clearly, there is much more work that could be done in this area. In particular, a broader sampling of both presses and libraries would provide a stronger basis for drawing conclusions about the trends in the relationship between the two. The addition of automated processes for extracting this data, if available, would make such an expansion much more feasible. Further, if access to publishers' records of sales to libraries over this period could be obtained, these could provide an invaluable point of reference for triangulation or potentially contestation of our results. Particularly given the vast differences between existing university press statements on this issue and the data presented here, it would be illuminating to examine and compare the underlying datasets for each. Still, the likelihood of gaining access to any such records - much less gaining access to records from a representative sample of presses - seems dubious at best.

Even given the limitations of the current study, however, these data provide sufficient evidence to begin to question the conventional wisdom on this issue: whatever is happening in the sphere of library purchasing of university press books, it seems unlikely that it conforms unproblematically to the parable presented in the introduction. Yes, serials prices have risen astronomically. Yes, monographic purchasing has been flat or in decline over the past few decades. But not all libraries are equal, and neither are all presses. It is important to recognize the breadth of academic library types that exist when making sweeping statements about "what libraries do;" it is equally important to recognize the special status of university press monographs in academia when comparing their treatment by academic libraries to that of monographs in general. We recognize that university presses are in economic trouble, and agree that the production and dissemination of new knowledge is an essential part of universities' missions. However, in searching for the best way to assure a robust system of scholarly communication going forward, it is important to first accurately diagnose the factors contributing to its current peril. This paper moves us closer to that initial aim.

\section{REFERENCES}

American Library Association. (2013, February). ALA Library Fact Sheet 1: Number of Libraries in the United States Retrieved from http:/www.ala.org/tools/ libfactsheets/alalibraryfactsheet 01

Association of American University Presses. (1987-2011). Directory [series]. New York: AAUP.

Association of College and Research Libraries. (2011). 2010 Academic library trends and statistics for Carnegie classification: Doctoral-granting institutions. Chicago: ACRL.

Association of Research Libraries. (2011). Monograph and Serials Costs in ARL Libraries 1986-2011. Retrieved from http://www.arl.org/storage/documents/monographserial-costs.pdf. 
Dougherty, P. J. (2010). Reimagining the University Press: A Checklist for Scholarly Publishers. Journal of Electronic Publishing, 13(2). doi: http://dx.doi.org/10.3998/3336451.0013.202.

Esposito, J. (2010). Stage Five Book Publishing. Journal of Electronic Publishing, 13(2). doi: http://dx.doi.org/10.3998/3336451.0013.204.

Esposito, J. (2012, February 22). Hawking Radiation: Figuring Out How Many Books Are Sold to Libraries. Retrieved from http://scholarlykitchen.sspnet.org/ 2012/02/22/hawking-radiation-figuring-out-how-manybooks-are-sold-to-libraries-2/

Greco, A. N., Jones, R. F., Wharton, R. M., \& Estelami, H. (2007). The Changing College and University Library Market for University Press Books and Journals: $1997-$ 2004. Journal of Scholarly Publishing, 39(1), 265-296.

Hitchcock, J. (1999). Reaching specialized audiences: the publisher's conundrum. In The Specialized Scholarly Monograph in Crisis, or, How Can I Get Tenure if You Won't Publish My Book? Washington, DC: Association of Research Libraries. Retrieved from http://www. arl.org/resources/pubs/specscholmono/Hitchcock.shtml.

Kyrillidou, M., Morris, S., \& Roebuck, G. (Eds.). (2011). ARL Statistics 2009-2010. Washington, DC: Association of Research Libraries. Retrieved from http://publications.arl.org/ARL-Statistics-2009-2010.

Kyrillidou, M., Morris, S., \& Roebuck, G. (Eds.). (2012). ARL Statistics 2010-2011. Washington, DC:

Association of Research Libraries. Retrieved from http://publications.arl.org/ARL-Statistics-2010-2011.
Lavoie, B., Connaway, L. S., \& Dempsey, L. (2005). Anatomy of Aggregate Collections: The Example of Google Print for Libraries. D-Lib Magazine, 11(9). Retrieved from http://www.dlib.org/dlib/september05/ lavoie/09lavoie.html.

Lavoie, B., Malpas, C., \& Shipengrover, J. D. (2012). Print Management at "Mega-Scale": A Regional Perspective on Print Book Collections in North America. Dublin, OH: OCLC Research. Retrieved from http://www.oclc. org/research/publications/library/2012/2012-05.pdf.

OCLC. What is WorldCat? Retrieved from http://www.worldcat.org/whatis/default.jsp

Pochoda, P. (2010). Editor's Note for Reimagining the University Press. Journal of Electronic Publishing, 13(2). doi: http://dx.doi.org/10.3998/3336451.0013.201.

Smallwood, S. (2002, September 20). The crumbling intellectual foundation, Chronicle of Higher Education, p. A10.

Stewart, C. (2011). An Overview of ACRLMetrics. The Journal of Academic Librarianship, 37(1), 73-76.

Thatcher, S. G. (1995, March 3). The Crisis in Scholarly Communication, Chronicle of Higher Education.

Thompson, J. B. (2005). Books in the Digital Age. Malden, MA: Polity Press.

Wasserman, M. (1998). Reprint: How Much Does It Cost to Publish A Monograph and Why? Journal of Electronic Publishing, 4(1). doi:

http://dx.doi.org/10.3998/3336451.0004.104. 